\title{
Correction to: Long-Term Prognostic Value of Coronary Computed Tomography Angiography
}

Takor B. Arrey-Mbi, MD

Seth M. Klusewitz, MD

Todd C. Villines, $M D^{*}$

\section{Address}

"Cardiology Service, Department of Medicine, Walter Reed National Military Medical Center, 8930 Brown Drive, Bld 9A, Room 2335, Bethesda, MD, 20889, USA

Email: todd.c.villines.mil@mail.mil

Published online: 16 May 2018

(C) US Government (outside the USA) 2018

The online version of the original article can be found at https://doi.org/10.1007/s11936-017-0588-5

Correction to: Curr Treat Options Cardio Med (2017) 19: 90

https://doi.org/10.1007/s11936-017-0588-5

The authors would like to note that this article published in Current Treatment Options in Cardiovascular Medicine journal is not showing Open Access on the website. Thus, the paper is still not available for free online. Open Access license information is provided below.

The original article has been corrected.

\section{Open Access}

This article is distributed under the terms of the Creative Commons Attribution 4.0 International License (http:// creativecommons.org/licenses/by/4.0/), which permits unrestricted use, distribution, and reproduction in any medium, provided you give appropriate credit to the original author(s) and the source, provide a link to the Creative Commons license, and indicate if changes were made. 